\title{
Management of Integral Ecological-Economic Processes in the «Coast-Sea» System
}

\author{
I.E. Timchenko, I.K. Ivashchenko, E.M. Igumnova \\ Marine Hydrophysical Institute, Russian Academy of Sciences, Sevastopol, \\ Russian Federation
}

\begin{abstract}
A model of ecological-economic system connected output of the economic subsystem "Coast" and the level of marine environment pollution controlled by the by the subsystem "Sea" is proposed. The model is constructed by the method of adaptive balance of causes and includes the management agents which permit to define the rate of economic sanctions applied to an enterprise for deterioration of the marine environment ecological condition. It is shown that this method for modeling of causeeffect relations in complex systems adequately describes regularities of behavior (known from the experience) of main economic variables in the "Coast" subsystem. These variables are prime cost and profit dynamics depending on penalties for marine environment pollution with production wastes. A method for introduction of these penalties by means of management agents in the "Sea" subsystem, which control the cases of exceeding the maximum allowable pollution level, is proposed. To verify the proposed methods for the "Coast - Sea" model management, a series of simulation experiments is carried out. It was determined that equation system of adaptive "Coast - Sea" model has the only stable solution. The examples of scenarios simulating conditions of balances between economic profit of production and the expenses required for protection of marine environment from pollution are presented. In particular, the scenarios which allow one to manage production dynamics by means of continuous control over the marine environment pollution level are constructed. The conclusion that the adaptive models of cause-effect relations between the integral economic and ecological processes in the coastal zone permit to find the conditions that provide rational environment management is drawn.
\end{abstract}

Keywords: ecological-economic model, adaptive balance of causes.

DOI: 10.22449/1573-160X-2015-3-58-71

(c) 2015, I.E. Timchenko, I.K. Ivashchenko, E.M. Igumnova

(C) 2015, Physical Oceanography

Introduction. One of the most important problems of nature management in the coastal zone is a sustainable development of the nature-economic complex "Coast - Sea". The main criterion of managing the complex development consists in dynamic balance between the economic expediency of natural resources' consumption and the ecological propriety (from the viewpoint of ecology) of interference in the environment natural state. Management of the resources of the coastal zone development consists in coordinating the purposes of industrial and service producers aimed at maximum profit, on the one hand, and the population interested in reducing pollution of the coastal and marine environment and in preserving its biodiversity $[1,2]$.

Solution of this problem requires the information technologies for managing the scenarios of natural resources' consumption and the methods based on these technologies of control the environment ecology. Similar scenarios can be simulated using the model of the ecological-economic system of the coastal zone. It provides a possibility to forecast such scenarios of nature management which will ensure both the economic efficiency of goods and services' production and the required amount of nature-conservative measures to compensate pollution of the coastal marine environment with production and household waste.

The investigations in the environmental economics are very intensive now. The authors of $[3,4]$ and many others make the attempts to formulate the principles of rational nature management. Along with the informal mathematical models of marine ecosystems [5] and the economic production systems [6], a modeling of 
joint ecological-economic systems is developed mainly through formalization of the cause-effect relations by the system dynamics method [7, 8]. Since it is difficult to combine the ecological and economic subsystems into a single model, modeling of the ecological-economic systems of the sea coastal zone is at its initial stage of searching the means for model construction.

A number of studies on this problem held in the Marine Hydrophysical Institute of RAS included development of adaptive models of the ecologicaleconomic systems of the sea coastal zone [9] based on the system concept of the adaptive balance of causes [10]. The modular structure and feedbacks permitting to manage the scenarios of the development processes are applied in the adaptive models. This makes it possible to improve stability of management due to use of non-linear management agents in the models.

In the present paper the authors consider the problem of managing the integral ecological-economic processes in the sea coastal zone which are developed in the model of the "Coast - Sea" generalized system. The purpose of the study is to couple (within the general management system) output of the economic subsystem "Coast" and the marine environment pollution level controlled by the subsystem "Sea". That is why both subsystems are considered in the most simplified form when the located on the coast industry is characterized by an amount of the generalized product, and the marine environment pollution - by a generalized index of the contamination degree.

Basic structural elements of the "Coast - Sea” system model. According to the principles of the system approach [10] the ecological-economic system model of the coastal zone has to be constructed starting from identifying the processes which correspond to the formulated purpose of modeling. In our case it means forecasting the scenarios of the interrelated economic and ecological processes which permit to assess the production economic efficiency and the state of marine environment ecology. Besides, the obligatory condition is the presence of the scenarios' management block permitting, by means of the simulation experiments, to find a rational mode of the coastal system functioning when the economic system operates efficiently and practically does not contaminate marine environment with its production waste.

Due to the complexity of the problem, at the initial stage it is advisable to use a generalized output aggregate of the economic system in the coastal zone which integrally reflects the total amount of the produced goods and services, i. e. the integral output volume. The production economic efficiency which depends on the ratio of incomes and expenses for a certain period can serve a criterion of the economic zone efficiency.

The integral characteristics of the ecological state of marine environment consist in the degree of the industrial waste pollution and in the general degree of its biodiversity. Each of these two indices is formed being effected by many various factors. The following relationships were used to simplify the process: the pollution level is conditioned by the balance between the rate of pollution accumulation and the rate of the marine environment self-purification resulting from chemical-bacteriological reactions and water mass mixing, and the biodiversity degree depends solely upon the pollution level.

Proceeding from these considerations, the structure of the integral processes' model of the sea coastal zone was proposed. It consists of the subsystem "Sea" representing the processes of pollution accumulation and transformation in the marine environment, and the subsystem "Coast" describing the economic processes that conditions production efficiency.

PHYSICAL OCEANOGRAPHY NO. 3 (2015) 
These considerations stipulated inclusion of the following integral ecologicaleconomic processes in the model structure:

- production prime cost $E$,

- pollution level (integral index) $P L$,

- production volume $V$,

- ecological fine for contaminating marine environment $T X$,

- amount of environment protection measures EP,

- demand for industrial products (external effect upon the system) $D$,

- cost of industrial production (external effect upon the system) $R$.

These processes are united in the cause-effect relations' system represented in Fig. 1.

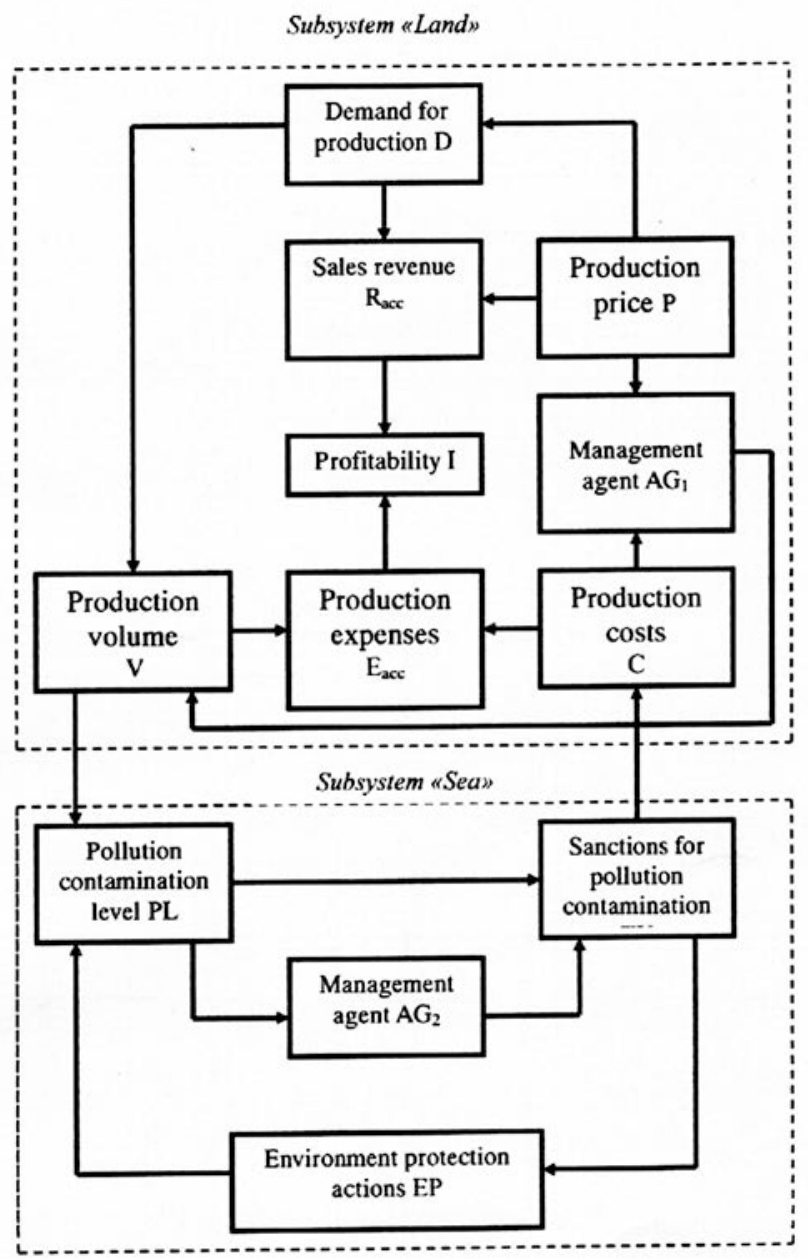

Fig. 1. Conceptual model of the "Coast-Sea” system

Being subjected to the external effect (demand D), the system produces output $\mathrm{V}$ spending the accumulated (in course of a certain period) material and financial resources $E_{\text {acc }}=E V_{\text {acc }}$ and drawing profit $R_{\text {acc }}=P V_{\text {acc. }}$. In the interests of production it is necessary to be sure that profit consistently exceeds expenditures. Therefore, 
the management agent AG1is included in the model structure. It stops production when the prime cost exceeds the market price of its products.

The ecological block of the model is structured in a following way. It is assumed that the environment pollution level resulted from production increases proportionally to the products' volume $V_{\text {acc }}$ accumulated during the period of the system management. Growth trend of the pollution level exists in the environment simultaneously with the tendency of its decrease. The reason of this tendency consists in the environment natural self-purification, for example, resulting from chemical and biological processes in the sea and turbulent mixing of air and water masses. In addition, decrease of pollution level is supported by the environment protection measures that restrict inflow of pollutants by introducing resourceconserving technologies.

In order to take into account the environment protection measures, the model structure includes ecological fines which are assumed to be proportional to the current production volume. When the level of the environment pollution exceeds the limit value $P L^{*}$ the management agent $A G_{2}$ starts to operate; it adds the ecological fine $T X$ to the taxes and, thus, directs it to the fund of environment protection measures EP. Thus, the beginning of production is accompanied by formation of the fund which is used for reducing the level of the environment pollution. The following condition is adopted in the model: decrease of the environment pollution level is proportional to the fund amount which depends on the accumulated amount of taxes and environmental fines $T X_{\text {acc. }}$.

Application of the method of adaptive balance of causes for constructing the model of the "Coast-Sea" system. The method of the adaptive balance of causes (ABC method) is based on the hypotheses on the adaptive balance of causes and on preservation of the environment resource capacity. The hypothesis on the adaptive balance of causes reflects the system's trend to dynamic equilibrium with environment. The balance of causes is realized through the continuous adjustment of the intra-system processes to each other, as well as to the changes taking place in the environment. The processes' intra-system interaction in the ecosystems is subjected, in particular, to the evolution laws of the living organisms surviving which have to adapt to the environment conditions. If we accept the hypotheses on the adaptive balance of causes, it is normal to assume that there is a certain general equation for the function representing the modeled process which reflects this function tendency to the state of dynamic equilibrium with other processes.

Such an equation was proposed in the ABC method developed for constructing adaptive models of the ecological-economic systems [10]. To deduce it, the equation right side containing the rate of the process $u(t)$ change through its values $u$ and $-u$ was supplemented with the basic influence functions $F^{(-)}(u)$ and $F^{(+)}(u)$ which provide balance of the positive and negative feedbacks. Then the equation of the process $u(t)$ takes the following form:

$$
\frac{d u}{d t}=F^{(-)}(u) u-F^{(+)}(u) u .
$$

PHYSICAL OCEANOGRAPHY NO. 3 (2015) 
The role of the basic functions is to restrain both growth and decay of the $u(t)$ function and to direct the equation solution tof a stable steady state. For this purpose it is sufficient to require that at $u$ growth in the area of its defining, the basic function $F^{(-)}(u)$ should monotonically decrease and the basic function $F^{(+)}(u)$ should monotonically increase. Then, to ensure general balance between the tendencies to growth and decrease of $u(t)$, it is necessary to apply the additional condition of normalizing the basic influence functions

$$
F^{(-)}(u)+F^{(+)}(u)=2 C,
$$

where $C$ is a constant the essence of whose becomes clear if the hypothesis on preserving the environment resource capacity is accepted.

Let us explain this hypothesis on the example of the marine ecosystem. The processes developing in the ecosystem can be considered as the responses of this system to the external effects under the condition that the processes' intra-system influences upon each other are balanced. Since all the interactions between the chemical and biological processes taking place in the given marine environment volume are realized at certain resource constraints, growth of concentration of any component in the ecosystem is always limited by the available resources of the reaction. The hypothesis on preservation of the environment resource capacity concerning the given reaction means that for each $u_{i}$ process there is a certain marine environment resource capacity $2 C_{i}$ (current capacity [11]) which conditions general resource potential of the process development.

It is convenient to attribute the $C_{i}$ values to the middle of the processes' variability intervals. Then the intra-system and external effects modifying the resources' possibilities of the process $u_{i}$ development are manifested in the fact that they deviate the process values from $C_{i}$ within its variability interval $\left(0, \max u_{i}=2 C_{i}\right)$.

For the system consisting of $n$ interrelated processes, it is convenient to accept the simplest representation for the basic functions [10]:

$$
F^{(+)}\left(u_{i}-\sum_{j=1}^{n-1} a_{i j} u_{j}-f_{i}\right)=u_{i}-\sum_{j=1}^{n-1} a_{i j} u_{j}-f_{i}, \quad(i, j=1,2, \ldots, n),(i \neq j),
$$

where $\sum_{j=1}^{n-1} a_{i j} u_{j}$ is the algebraic sum of the intra-system effects, $f_{i}$ are the external effects, $a_{i j}$ is the influence coefficient. Then the total system of the $A B C$ method module equations takes on the following form

$$
\frac{d u_{i}}{d t}=2 r_{i} u_{i}\left\{C_{i}-\left[u_{i}-\sum_{j=1}^{n-1} a_{i j} u_{j}-f_{i}\right]\right\} \text {. }
$$


It follows directly from equation system (3) of the $A B C$ method that the stable stationary solution of equation system $\left\{u_{i}^{*}\right\}$ corresponds to the following condition:

$$
u_{i}^{*}-\sum_{j=1}^{n-1} a_{i j} u_{j}^{*}-f_{i}=C_{i},
$$

which expresses the essence of the hypothesis on maintaining the environment resource capacity.

Thus, while adapting to each other and to the external effects applied to the system, the $A B C$ model variables take on the values that satisfy relation (4). Practical significance of this relation is that it imposes restrictions on choice of the influence coefficients $a_{i j}$ in the adaptive models of complex systems. To control fulfillment of condition (4), the management logic operators (agents) should be used in such models.

Construction of a formal model of the "Coast - Sea" system by the method of the adaptive balance of causes. Let us write down the equation system in the model of the ecological-economic system "Coast-Sea" using the method of the adaptive balance of causes. For this purpose all the modeled processes should be represented in a dimensionless form. In [10] it is proposed, simultaneously with deducing the model variables to the dimensionless form, to introduce general variability interval for them, for example, $(0,10)$. Then the model simulated processes' scenarios are conveniently represented on common coordinate axes; it makes their comparison much easier. The corresponding linear transformation in the present case will be of the following form:

$$
u_{i}=\frac{u_{i}^{\prime}}{\max \left(u_{i}^{\prime}\right)} 10=\frac{u_{i}^{\prime}}{2 \bar{u}_{i}^{\prime}} 10=5 \frac{u_{i}^{\prime}}{\bar{u}_{i}^{\prime}} .
$$

In this expression $u_{i}^{\prime}$ are the model dimensional variables, $\bar{u}_{i}^{\prime}$ are their known average values, and $\max \left(u_{i}^{\prime}\right)=2 \bar{u}_{i}^{\prime}$ are their maximum values. Then the model equation system shown in Fig. 1 can be represented in a form of the module equations (3) of the $A B C$ method in which the resource capacities are assumed to be equal to 10 dimensionless units, and $C_{i}=5$ :

$$
\begin{gathered}
\frac{d D}{d t}=2 r_{D} D\left[5-\left(D-a_{D / P} P-F_{D}\right)\right], \\
\frac{d P}{d t}=2 r_{P} P\left[5-\left(P-F_{P}\right)\right], \\
\frac{d E}{d t}=2 r_{E} E\left[5-\left(E-a_{E / T X} T X-F_{E}\right)\right], \\
\frac{d V}{d t}=2 r_{V} V\left[5-\left(V-a_{V / D} D-A G_{1}\right)\right],
\end{gathered}
$$




$$
\begin{gathered}
\frac{d P L}{d t}=2 r_{P L} P L\left[5-\left(P L-a_{P L / V} V_{a c c}+a_{P L / E P} E P+F_{P L}\right)\right], \\
\frac{d T X}{d t}=2 r_{T X} T X\left[5-\left(T X-a_{T X / P L} P L-A G_{2}\right)\right], \\
\frac{d E P}{d t}=2 r_{E P} E P\left[5-\left(E P-a_{E P / T X} T X_{a c c}+F_{E P}\right)\right], \\
A G_{1}=I F\left[P>E ; 0 ; A_{1}\right], \\
A G_{2}=I F\left[P L<P L^{*} ; 0 ; \operatorname{PPL}\left(1-\exp \left(-\alpha_{P L} \tau\right)\right)\right], \\
U_{a c c}=\int_{0}^{t} U(t) d t, \quad U=[V(t) ; T X(t) ; P L(t) ; E P(t) ; E(t) V(t) ; P(t) D(t)],
\end{gathered}
$$

where $r_{M N}$ are the relation of the specific rates of the variables' change to the very variables; functions $F$ represent external management: $F_{D}$ is the dynamics of the demand for products, $F_{P}$ is the production market value, $F_{E}$ are the field costs, $F_{P L}$ is the marine environment self-purification resulting from water mixing and chemical-bacteriological reactions, $F_{E P}$ is reduction of the $E P_{\text {acc }}$ fund due to the environment protection measures; $\theta$ is the coefficient of penalty influence.

To perform simulation experiments, the equation system (5) was represented as finite differences. The equations' coefficients were chosen experimentally in such a way that the variables' values should not exceed the maximum permissible value $\max u_{i}=10$. The calculation step was 0.1 , and the modeling time interval equaled 500 steps. The parameters $r_{M N}$ characterizing relative variability of the process were taken to be equal to 1 . Average values of the dimensionless variables $\bar{u}_{i}=5$ were used as the initial values for the equations. In order to control the environment pollution level by industrial waste, its allowable value, $P L^{*}=7$, was accepted and the range of values $(6.5,7.5)$ was defined; the $P L$ value in it is to be kept by the fines for exceeding the $P L^{*}$ level. For the functions of the marine environment self-purification and change in the environment protection fund value, the linear approximations were accepted: $F_{P L}=\beta P L_{\text {acc }}$ and $F_{E P}=\delta E P_{\text {acc }}$. In the iterative processes of the equations (5) solution, fulfillment of the condition of the resource capacity preservation (4) was controlled by the management agents of the following type

$$
u_{i}^{k+1}=\operatorname{IF}\left[u_{i}^{k}<0 ; 0 ; \operatorname{IF}\left(u_{i}^{k}>10 ; 10 ; u_{i}^{k}\right)\right] .
$$

The plan of the experiments was as follows. Initially the processes' scenarios had to be calculated at constant values of the external effects: demand for products $D$ and the market cost of products $P$. At that the equations' coefficients and the model parameters were specified in such a way that the pollution fines should not be excessively high for industrial production and could not stop it because of profit absence. Then the external effects upon the production should be included in a 
form of a variable demand for the products, and the model sensitivity to the external effects, i. e. its controllability, should be estimated.

After checking adequacy and controllability of the scenarios reproduced by the model under the conditions of variable demand, the task was to estimate uniqueness of the solutions of the model computational algorithm. And finally, it was necessary to show how the dynamics of production profit changed and how the scenarios of the environment pollution level depended upon the penalty amount imposed on industrial production.

Numerical experiments based on the model of the ecological-economic system "Coast-Sea". In the first numerical experiment the model did not include dependence of demand for production upon its price $P$ and the external effects upon the demand, price and prime cost were not taken into account: $F_{D}=F_{P}=F_{E}=0$. The coefficients' values in the functions $F_{P L}$ and $F_{E P}$ were equal $-\beta=\delta=0,01$. The calculation results are represented in Fig. 2. Consider the scenario shown in Fig. 2, $a$. Since the prime cost of production $E$ at the beginning of the experiment was lower than its price $P$, the industry, being influenced by the demand $D=3.5$, began to output products. Simultaneously with the products output, the marine environment pollution began to increase that is confirmed by the scenario of pollution level $P L$ in Fig. 2, $b$. The ecological fine $T X$ grew proportional to the pollution level. When the pollution level reached the threshold value $P L^{*}=7$, the management agent $A G_{2}$ (Fig. 2, $c$ ) began to increase the pollution penalties supplementing the environmental fine with the ecological penalty for exceeding the threshold value $P L^{*}$. As the prime cost of production depended on the environment protection tax, its value increased rapidly (Fig. 2, $a$ ). As a result, the prime cost began to exceed the price of products, the production became unprofitable, and the management agent $A G_{1}$ (Fig. 2, c) suspended the production output. Further, the cycle of these operations continued.

The management agents' functions are shown in Fig. 2, $c$. The management agent $A G_{1}$ suspended production each time when the production prime cost exceeded the products' price. However, the production output was resumed with some delay. The delay time depended on choice of the constant value $A_{1}$ in the logical operator

$$
A G_{1}=I F\left[P>E ; 0 ; A_{1}\right]
$$

and on the value of demand $D$. The numerical experiments showed that the higher the value $A_{1}$, as compared to the value $a_{V / D} D$, the longer the delay of the output resumption. This is explained by the feature of the applied iterative scheme of the equation solution for the production output volume $V$ : increase of difference $A_{1}-a_{V / D} D$ is accompanied by increase of the iterations' number which provide solutions of this equation. This circumstance was found to be corresponding to the modeling task as in practice the resuming of production output can be associated with the actual time delay.

Fig. 2, $d$ displays dynamics of profit accumulation by the subsystem "Coast" taking into account suspensions of production and sales of products due to 
penalties. Note that this graph shows the value of the total profit accumulated from the beginning of the experiments up to the current time. Difference between the accumulated incomes $R_{\text {acc }}$ and the accumulated expenses $E_{\text {acc }}$ is given in the conditional units. It follows from this graph that production remained profitable even under the penalties which hold the pollution level $P L$ within the acceptable limits (Fig. 2, b).
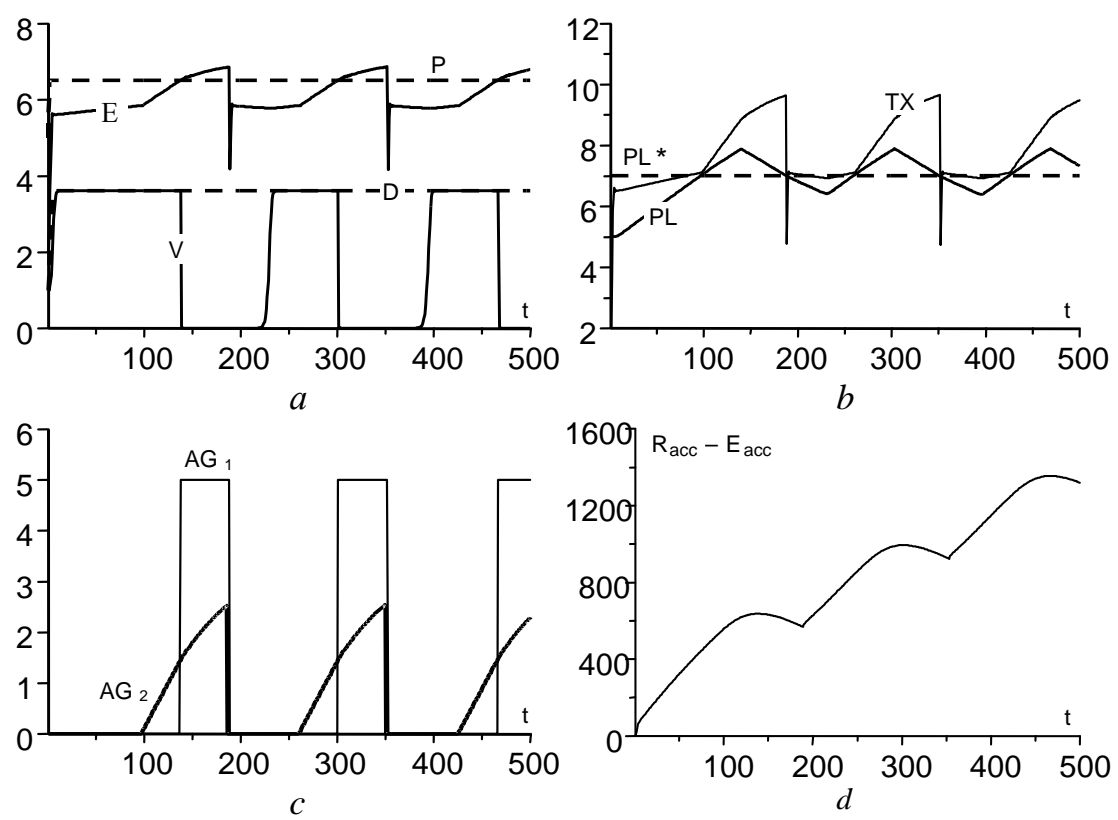

Fig. 2. Scenarios of ecological-economic processes at constant demand for products of the "CoastSea" system: $a$ - suspension of production when the primary cost $E$ becomes higher than the price $P$, and delay in resuming the production output due to low demand; $b$ - increase of environmental penalties TX when the pollution level PL exceeds the acceptable value $P L^{*} ; c$ - functions of the output management agent $A G_{1}$ and the penalties' management agent $A G_{2} ; d$-difference between the accumulated during the experiment income $R_{\mathrm{acc}}$ and the expenses $E_{\text {acc. }}$

In the second numerical experiment we considered behavior of the "CoastSea" system when it was subjected to the external managing effect $F_{D}$ in a form of a changing in time demand for production. The results of the experiment are in Fig. 3. The simulated graph of demand is shown in Fig. 3, $a$. As compared to the case of constant demand, the processes' scenarios were significantly changed. During the initial period, when the demand grew rapidly, the rate of production output and pollution increase mounted quicker than in the experiments with constant demand. Therefore, the environmental fine value and the production prime cost exceeded the upper limit of the variation range prescribed earlier and equal to 10 . The agent controlling this interval framework limited the values of $T X$ and $E$ by their limiting values.

The first production suspension occurred at the $110^{\text {th }}$ step of simulations when the demand value was 5.5. It is seen in Fig. 3, $b$ that starting from this moment the pollution level began to decrease. However, due to high demand, the value of difference $A_{1}-a_{V / D} D$ in the equation for the production output volume $V$ proved to 
be insufficient to resume the production immediately after its first suspension. Therefore, up to the moment when the pollution level decreased to $P L^{*}$, there was a partial output of production (graph $V$ in Fig. 3, a). The production was resumed completely at the $310^{\text {th }}$ step when the condition $P L=P L^{*}$ was achieved. After that the cycle of pollution growth and subsequent suspension of production was repeated on the $350^{\text {th }}$ step.
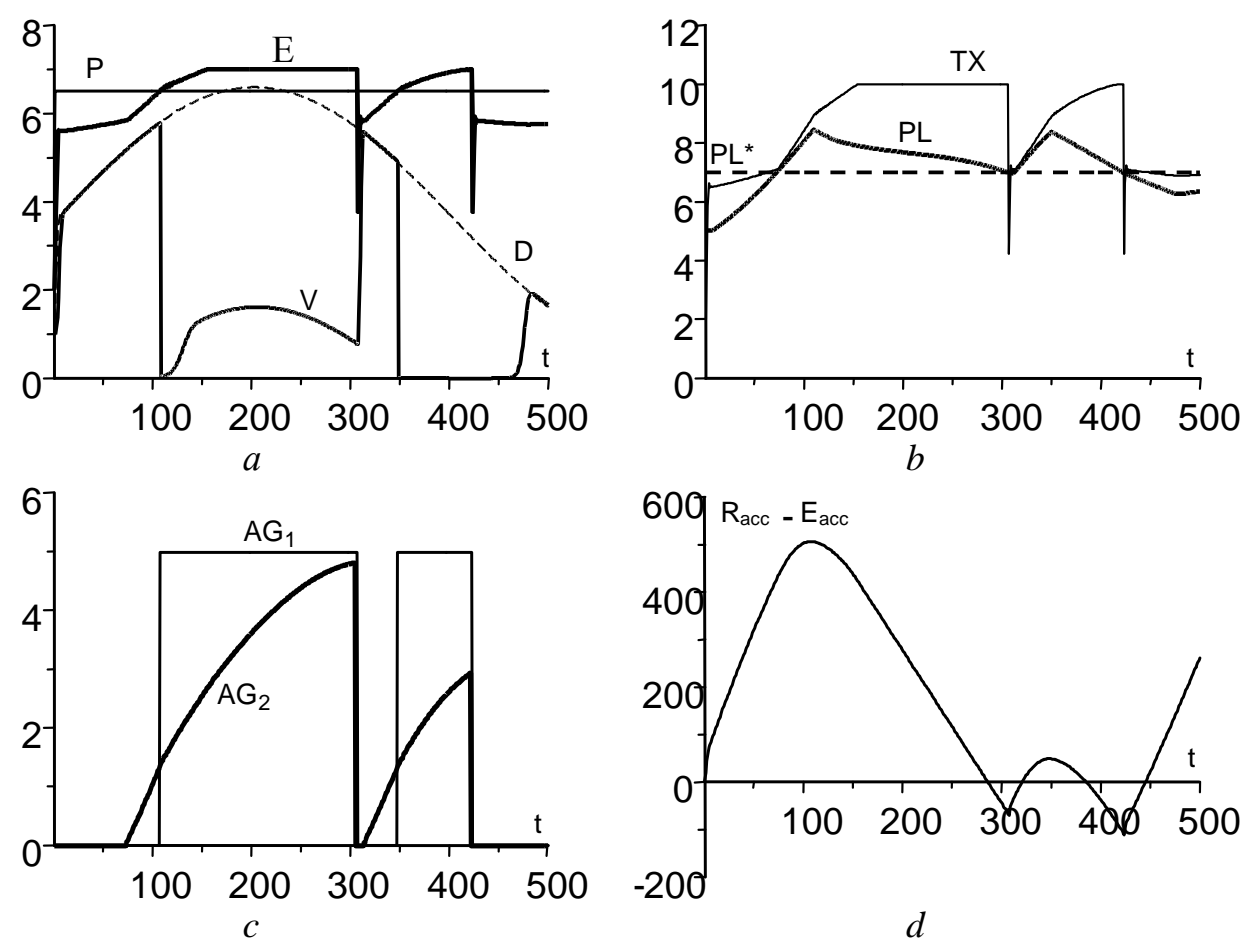

Fig. 3. Scenarios of the ecological-economic processes at a variable demand for the products of the "Coast-Sea" system: $a$ - suspension of production when the primary cost $E$ becomes higher than the price $P$, and delay in resuming the production output due to change of the difference value $A_{1}-a_{V / D} D ; b$ - dynamics of the ecological fine $T X$ and the pollution level $P L$; c - functions of the output management agent $A G_{1}$ and the penalties' management agent $A G_{2} ; \mathrm{d}$-difference between the accumulated during the experiment income $R_{\text {acc }}$ and the expenses $E_{\text {acc. }}$

Note that the second suspension was during a rapid demand decrease when the value of difference $A_{1}-a_{V / D} D$ in the equation for the production volume increased. Therefore, there was a delay in resuming the production output: the prime cost decreased below the price on the $430^{\text {th }}$ step, and the output was resumed at approximately the $470^{\text {th }}$ step of simulations (Fig. 3,a).

The numerical model of the "Coast-Sea" system permits to verify existence and uniqueness of solutions of its equation system (5). Note that theoretical analysis of the conditions of existence and uniqueness for the system of two logistic equations was performed in many studies on mathematical biology in connection with studying the "predator-prey" problem [11]. Apparently, yet there are no general results for the systems of logistic equations of higher order [12].

PHYSICAL OCEANOGRAPHY NO. 3 (2015) 
However, for the concrete numerical model (5) there was a possibility to assess the solutions' existence and uniqueness by geometric constructions. For this purpose, for the considered above cases of constant and variable demand for the system products, the graphs of the left and right parts of the model finite-difference equations were constructed. A set of curves depicting these graphs is shown in Fig. 4. In each case the line $n$ denoting in Fig. $4, a$, b the graphs of the left parts of the model finite-difference equations, crosses the corresponding graphs of the right parts only in one point; it testifies to existence and uniqueness of the equation system solution (5).

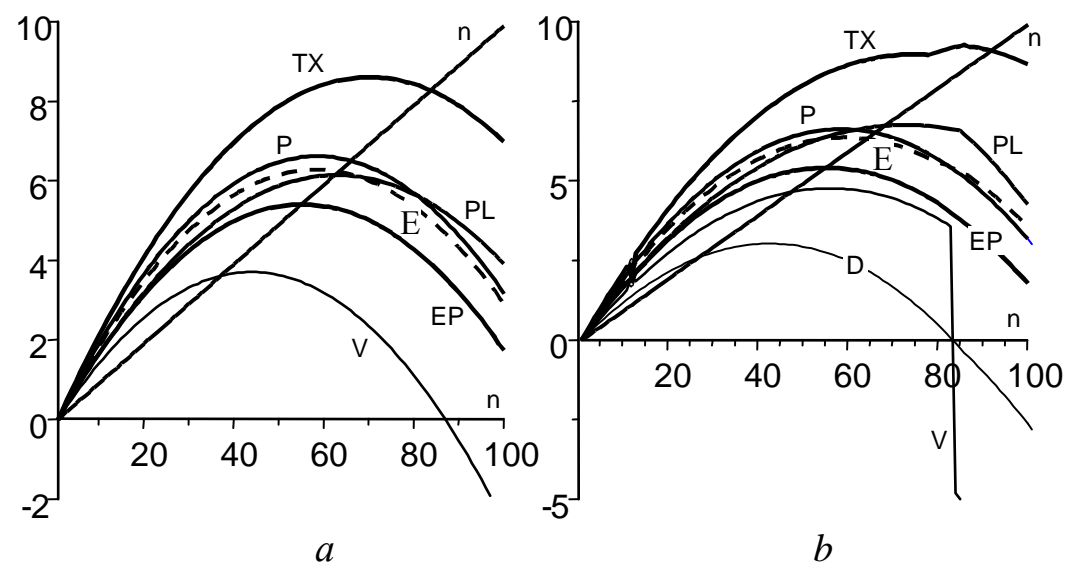

Fig. 4. Verification of existence and uniqueness of solutions of the model equation system illustrated by the graphs of the left (line $n$ ) and right parts of the finite-difference equations (5): $a$ - for constant demand, $b$ - for variable demand

Impact of ecological penalties for environment pollution upon the scenarios of economic processes. Practical significance of the models of the "Coast - Sea" system consists in the fact that they can be used for obtaining the estimates of the managing effects which establish the required balance between the production profit and the production-induced level of the marine environment pollution. One of the important managing factors is the value of ecological penalties (taxes and fines) for the environment pollution.

Consider how the processes' scenarios in the system depend on choice of the amount of these penalties. Their value is conditioned by the influence coefficient value $a_{T X / P L}$ in summand $a_{T X / P L} P L$ in the right part of the equation for the $T X$ and also by choice of parameter $\theta$ in the equation for the management agent $A G_{2}$. To assess the effect of penalties, let us construct the scenarios of the ecologicaleconomic processes at constant coefficient of environment protection tax $a_{T X / P L}=$ $=0.3$ and different values of $\theta$. Assume, for example, that $\theta=0.5$. The processes' scenarios in the system take on the form shown in Fig. 5, $a-d$. The calculation results represented in Fig. 3 were obtained at $\theta=0.3$. Comparison of this figure with Fig. 5 shoes that increase of the coefficient of the penalties' influence $\theta$ is accompanied by decrease of deviation of the pollution level from the permissible value $P L^{*}=7$. But at the same time the accumulated profit also decreases. That is why in order to define the penalties' value satisfying ecological and economic 68 
balance of the "Coast-Sea” system, it is necessary to possess a set of the processes' scenarios constructed for various values of parameter $\theta$.
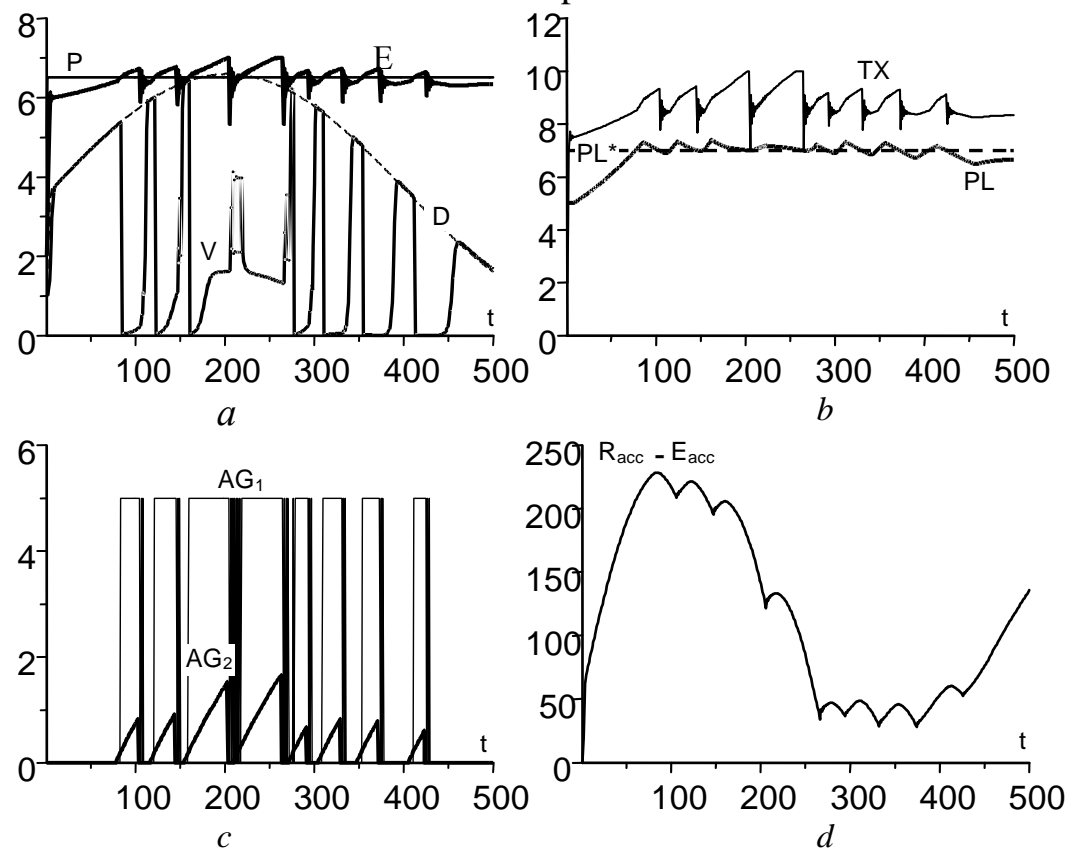

Fig. 5. Scenarios of the ecological-economic processes at a variable demand for the products of the "Coast - Sea" system for the case when the coefficient of the penalties influence $\theta=0.5: a$ - demand $D$, prime cost $E$ and production output $V ; b$ - ecological fine $T X$ and dynamics of the pollution degree $P L$; c - functions of the management agents $A G_{1}$ and $A G_{2} ; d$-dynamics of total profit

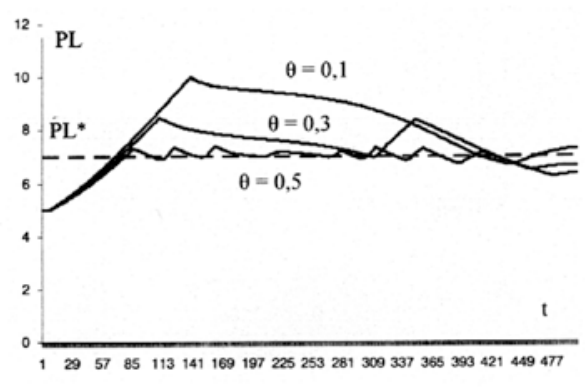

$a$

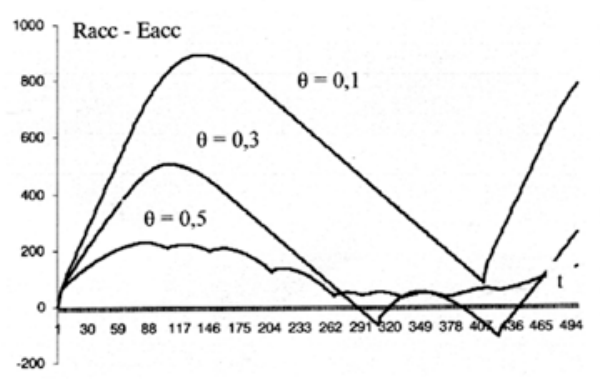

b

Fig. 6. Scenarios of the ecological and economic processes in the "Coast-Sea" system at various values of the influence coefficient of penalties for environment pollution $\theta$ : $a$-dynamics of the marine environment pollution level; $b$ - dynamics of production profit

PHYSICAL OCEANOGRAPHY NO. 3 (2015) 
An example of such scenarios' family is shown in Fig. 6. At the influence coefficients that were preset in the simulations, the most favorable of all the penalties was the one corresponding to $\theta=0.5$. It follows from Fig. 5, $a, b$ that at such penalties the prime cost of production increased on the average by $10 \%$, the pollution level was within the permissible limits, and the total profit of the "Coast Sea" system remained positive.

Conclusion. The results of the experiments show that the adaptive model of the ecological-economic system "Coast - Sea" based on the known cause and effect relations between the economic and the ecological processes provides the estimates of the production profitability and the environment ecological state. The obtained results permit to draw the following conclusions:

- the simulation model of the system "Coast - Sea" constructed by the method of adaptive balance of causes adequately describes the known behavior regularities both of the basic economic variables - prime cost and profit and the environment ones - the environment pollution level and the value of the environment protection fund formed due to penalties;

- application of the management agents (logical operators) in the model makes it possible to control the conditions of balance between the economic and ecological variables;

- the model equation system at the chosen coefficients and parameters is stable and has a unique solution;

- results of the simulation experiments confirm a possibility of defining such penalty values for polluting the environment which provide reasonable balance of nature management.

Note that these results were obtained using a relatively simple model of the ecological-economic system. The module principle for constructing equations, being applied in the adaptive models, permits to increase significantly a number of variables and to proceed from description of the integrated processes to the less averaged ones. The next steps in this direction can become the following ones: taking into account of the production resource capacity in the subsystem "Coast" and construction of the model of the biodiversity index formation in the subsystem "Sea".

Acknowledgements. The study was supported by the Russian Foundation for Basic Research grant № 14-45-01013 / 14.

\section{REFERENCES}

1. Timchenko, I.E., Igumnova, E.M. 2005, "Modelirovanie protsessov ustoichivogo razvitiya territoriy [Modeling of the processes of the territories' sustainable development]”, Simferopol, Tavrich. Nats. Univ., 132 p. (in Russian).

2. Ivanov, V.A., Igumnova, E.M. \& Timchenko, I.E., 2012, Coastal Zone Resources Management, Kyiv, Akademperiodika, 304 p. (in Russian).

3. Daly, H., Farley, J., 2010, “Ecological Economics: Principles and Applications”, $2^{\text {nd }}$ edition, Washington, Island Press, 544 p.

4. Voinov, A., 2008, “Systems Science and Modeling for Ecological Economics”, Academic Press, $430 \mathrm{p}$. 
5. Oguz, T., 2007, “Nonlinear response of Black Sea pelagic fish stocks to over-exploitation”, Mar. ecol. progr. ser., vol. 345, pp. 211-228.

6. Petrov, A.A., Pospelov, I.G., 1979, "Sistemny analiz razvivayushcheysya economiki: $k$ teorii proizvodstvennykh funktsiy, chasti $I-I V$ [Systems analysis of the developing economy: to the theory of production functions, parts I - IV]”, Izv. AN SSSR, Tekhn. Kibernetika, no. 2-5, pp. 492-506 (in Russian).

7. Forrester, J.W., 1968, Principles of Systems, Cambridge, MA, Productivity Press, 338 p.

8. Meadows, D.H., Meadows, D.L. \& Randers, J., 1992, Beyond the limits: Confronting Global Collapse, Envisioning a Sustainable Future, Post Mills, VT, Chelsea Green, 342 p.

9. Timchenko, I.E., Igumnova, E.M., 2011, “Upravlenie ekologo-ekonomicheskimi protsessami $v$ integral'noy modeli pribrezhnoy zony moray [Management of ecological-economical processes in the integral model of the sea coastal zone]”, Morskoy gidrofizichesky zhurnal, vol. 1, pp. 48-66 (in Russian).

10. Timchenko, I.E., Igumnova, E.M. \& Timchenko, I.I, 2000, "Sistemny menedzhment i ABStekhnologii ustoichivigo razvitiya [System management and $A B C$-technologies of sustainable development]", Sevastopol, MGI NAN Ukrainy, 225 p. (in Russian).

11. Murray, J.D., 2008, Mathematical Biology. II: Spatial Models and Biomedical Applications, Springer, $736 \mathrm{p}$.

12. Svirezhev, Yu.M., Logofet, D.O., 1978, “Ustoichivost’ biologicheskikh soobshchestv [Sustainability of biological communities]”, Moscow, Nauka, 352 p. (in Russian). 